\title{
SLOW-MOVING LANDSLIDE MONITORING WITH MULTI-TEMPORAL TERRASAR-X DATA BY MEANS OF DINSAR TECHNIQUES IN CROTONE PROVINCE (SOUTHERN ITALY)
}

\author{
Confuorto P. (1), Plank S. (2) Di Martire D. (1), Ramondini M. (3), Thuro K. (4), Calcaterra D. (1) \\ (1) Department of Earth, Environmental and Resources Sciences, Federico II University of Napoli; Largo San Mar- \\ cellino 10, 80138 Napoli, (Italy) \\ (2) German Remote Sensing Data Center (DFD), German Aerospace Center (DLR); Oberpfaffenhofen, Münchener \\ Straße 20, 82234 Weßling (Germany) \\ (3) Department of Civil, Architectural and Environmental Engineering, Federico II University of Napoli; Via Claudio \\ 21, 80125 Napoli ( Italy) \\ (4) Chair for Engineering Geology, Technische Universität München (TUM); Arcistraße 2, 80333 Munich (Germany)
} Email: pierluigi.confuorto@unina.it; simon.plank@dlr.de; diego.dimartire@unina.it; ramondin@unina.it; thu-
ro@tum.de; domenico.calcaterra@unina.it.

\begin{abstract}
The Differential SAR Interferometry (DInSAR) is one of the most powerful devices for monitoring deformation processes on the Earth surface. Here, a dataset of TerraSAR-X StripMap imagery covering almost the whole Crotone province territory, located in the south of the Italian peninsula, has been selected and processed. The time span goes from April 2008 to June 2010. In this work, two different multitemporal interferometry (MTI) approaches and two different software packages have been used and compared in order to identify benefits/constraints of each MTI approach and each software. Such approaches are: the 'permanent' (or 'persistent', or 'point-like') scatterers [1] implemented on the SARscape ${ }^{\circledR}$ software [2], and the Temporal Sublook Spectral Coherence (TSSC), derived from Coherent Pixel Technique algorithm and works on SUBSOFT processor, developed by the Remote Sensing Laboratory (RSLab) group, from the Universitat Politècnica de Catalunya (UPC) [3-5].
\end{abstract}

\section{INTRODUCTION}

Landslides represent one of the most remarkable and noticeable natural hazards, affecting both people and buildings and infrastructure, often causing loss of lives or of socio-economical values. Italy is one of the European countries most involved by these phenomena. Every year it is possible to count about a hundred "main landslide events", causing casualties, evacuations and damage to primary infrastructures and buildings, according to [6], redacted by the ISPRA (Italian institute for the Environmental Protection and Research). Such a high number has to be attributed to the geological and geomorphological context of the Italian territory, but also to an incorrect land management, started during the economic miracle in the early 60's. In particular, landslides characterized by slow to mod- erate kinematic are largely common in Central and Southern Italy: some of the most recent cases which can be mentioned are Agnone [7-8], Montaguto [9], Moio della Civitella [8-10-11]. These slope movements are characteristic, with a long evolutionary history, and with several reactivations of the already deformed mass, due to extraordinary rain or seismic events, and at times due to the human action. The monitoring of these phenomena is becoming more and more significant, not only for the scientific community, in order to prevent and forecast their effects. Nowadays, remote sensing represents a rapid and valuable tool for the landslide monitoring. Among the remote sensing techniques, the Differential SAR Interferometry is a useful device for mapping and monitoring landslides [12-18]. Different DInSAR approaches have been developed in the last 15 years, being able to detect and analyse large datasets of SAR images acquired on the same area in different times. Moreover, the development of the socalled Multi Temporal Interferometry (MTI), which overcome some of the limitations of conventional differential SAR interferometry [19], successfully improved the analysis and the monitoring of the landslide events. The availability of Very High Resolution images (VHR), deriving from new generation of sensors also contributed to a better landslide monitoring and to a better geomorphological investigation.

Two different techniques available on two software have been applied for this case study, in order to identify the benefit and the constraint of each MTI approach and each software. The dataset available for this paper is composed of TerraSAR-X images, acquired both over ascending and descending orbit, covering almost the whole Crotone province (Southern Italy) (Fig.1). The Crotone province territory is very prone to ground displacement phenomena. Several cases have been reported, as Cirò, Papanice, Cutro, San Mauro Marchesato, Santa Severina. In this paper, the landslide phe- 
nomena occurred in the locality of Papanice have been analysed, and a comparison among the different results have been performed. Several reactivations of landslides caused serious damage to the settlements. With the application of the MTI interferometry it has been possible to identify the precursor stages of these displacement events, thus confirming the effectiveness of such tools for provisional purposes.

\section{TEST SITE AND DATA}

Crotone province is located in the southern part of the Italian peninsula, to be more precise, in Calabria region, considered the tip of the 'Italian boot' (Fig. 1).

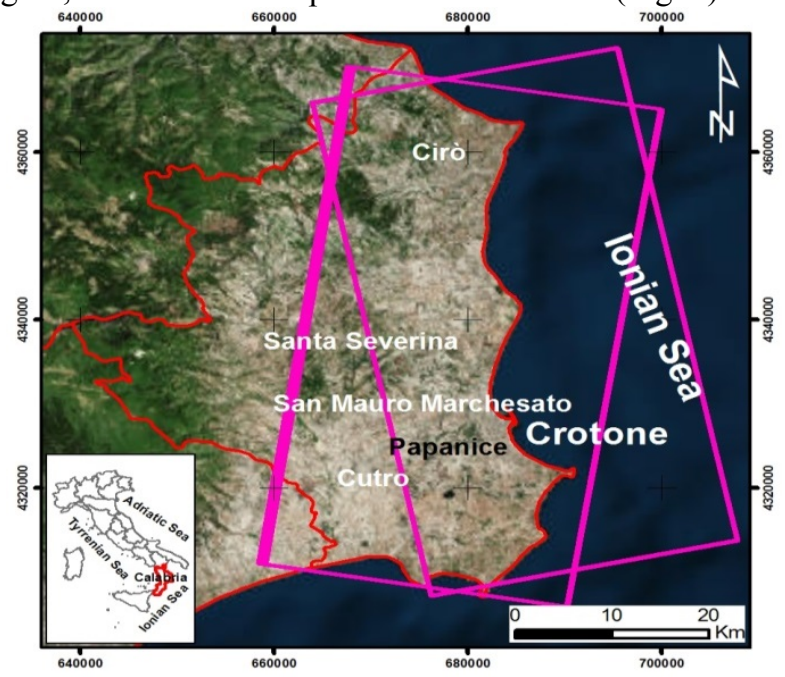

Figure 1. Location of the study area. The purple rectangles show the TerraSAR-X footprint, for the descending and the ascending orbit

The geological setting of this area is characterized by a large sedimentary basin (Crotone basin). The evolution of the above-mentioned basin began between Middle to Upper Miocene (Serravallian and Tortonian) [20-21]. It is bounded by two main shear-zones, with a NWtrending, the first one, located in the northern part is called Rossano-San Nicola shear zone, the latter is the Petilia Sosti shear zone, sited in the southern part [2125]. Papanice is a locality of Crotone municipality, 11 $\mathrm{km}$ far from the city center, located on the top of a NW-SE trending hill. The setting of the study area is included in the most recent part of the Crotone basin, composed by marine deposits of Pleistocene age. According to the geological map [26] and to a geological survey it is possible to affirm that the most recent formation of the Crotone basin is present in Papanice and its surrounding area: the substrate is made up of the Cutro Clay formation, of Middle-Calabrian time, with a local thickness of about few hundreds of meters. This formation is mainly composed of marly and silty claystones[20-27-28] and at times it is possible to recognize layers up to $1 \mathrm{~m}$ thick. The highest part of the geo- logical series is represented by the marine terrace deposits of Cutro Terrace, called S. Anna synthem, composed of sands and conglomerates, locally with intercalation of bioclastic limestones. Both the geological units do not present any tectonic and stress deformation, however both of them demonstrate a weak strength to erosion and a permeability from average to low. Papanice suburb has always been considered as unstable, as it is possible to note through the Landslide Inventory Map, reported in the Hydrogeomorphological Setting Plan (HSP) of the 2001 (Fig. 2a).

The landslides object of this paper can be considered as reactivations of dormant landslides. The slopes where these phenomena occurred are subjected to a strong evolution, mostly due to occasional and abundant precipitation, reactivating the hydrographic system and accelerating the instability. The landslides' reactivation took place on 23rd of February 2012, in two different points: one in the Pironte district (Via Piave) (Figs. 2b and $2 \mathrm{c}$ ) and the other one at the base of the primary school of Viale Oceania. The most important triggering factor for this reactivation was represented by the copious rainfalls occurred the days preceding the date of the main event: the Papanice rain gauge showed a cumulated rainfall value of $185 \mathrm{~mm}$ in the 3 days before the event, $108 \mathrm{~mm}$ in the day before. These are clearly outlier values for the local climate and for this kind of geomorphological context. Another instability factor is represented by the urban growth of the Pironte district, in the last 50 years, that could have probably modified the geotechnical, hydrological and geomorphological aspects of the area.

As regards the morphology of the landslide, a clear evidence is constituted by a fracture along Via Piave, 140 $\mathrm{m}$ long, and longitudinally deep evidence are visible till a dirt road below the houses, and superficial signs on the whole slope. Several damage and cracks on the buildings prominent to the slope have been easily recognized and five buildings have been involved by this movement, forcing people to abandon their houses and their activities. A dataset composed of 66 TerraSAR-X StripMap Single Look Complex (SLC) images for the ascending stack, and 67 for the descending one, covering the time interval between April 2008 and June 2010, has been obtained thanks to the participation to two Announcements of Opportunity for the exploitation of archive images (GEO1589 - GEO2641). Such stacks are characterized by a temporal sampling of 11 days. Furthermore, a high resolution $(5 \mathrm{~m} \times 5 \mathrm{~m})$ Digital Terrain Model (DTM), obtained from the Regional Topographical Map (scale 1:5000) has been used to subtract the topographic component of the interferometric phase. Starting from the entire SLC image, a crop of $2 \mathrm{~km} \times 1,5 \mathrm{~km}$ has been selected to define the area of interest. 

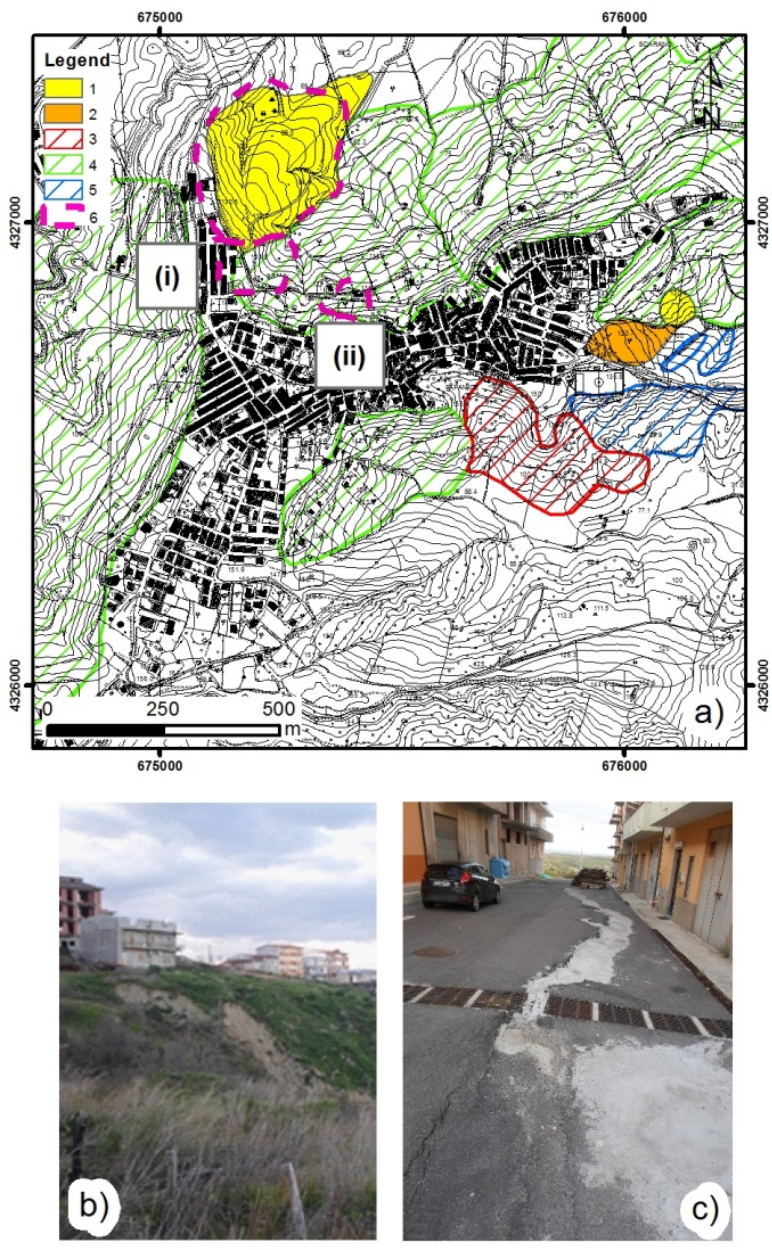

Figure 2. a) 2001 HSP Landslide inventory map, 1: Slide; 2: Complex landslides; 3 Shallow landslide area; 4: Deep landslide area; 5 Erosional area; 6: Landslides mapped through the field survey. b) Oblique view of the Via Piave landslide. c) Main scarp of the Via Piave landslide

\section{METHODS}

To monitor the identified instability phenomena, two different DInSAR approaches have been successfully applied, in order to obtain the measurements of the displacements and the related time series. A first approach has been made with the Temporal Sublook Spectral Coherence, implemented on the SUBSOFT processor, developed by the Universitat Politecnica de Catalunya of Barcelona, Spain [4]. As for the usual DInSAR processing chains, the crucial step is the pixel selection. Such step consists of the detection of reliable pixels, because, due to decorrelation artefacts, not all the pixels present enough phase quality for the processing. One of the main advantages of such approach is that TSSC is not influenced by the possible amplitude variations along time. Therefore, the amplitude is not a consistent parameter in the TSSC estimation, making the radiometric calibration unnecessary. Moreover, working as 'point-like', the full-resolution is preserved in comparison with the coherence stability pixel selection approach. A more detailed description of the technique can be found in [5]. A second criterion adopted is the PSI [1], implemented in the SARscape software. The PSI, instead, is a technique belonging to the PS category and is an algorithm successfully used for long series of SAR data, in order to estimate and remove the atmospheric effects [1]. In this case, the pixel selection is made through the Amplitude Dispersion Index (D), defined as the ratio between the temporal average of the amplitude for a certain pixel and the temporal standard deviation (Eq.1).

$$
D_{a}=\frac{\mu}{\delta}
$$

The final result of the PSI is an accurate measurement of the movements along the SAR Line Of Sight (LOS velocities) of each PS, respect to an assumed reference point (considered as stable), in the time interval considered. A PS is characterized by long term high coherence in all the SAR images considered in the time interval [1]. Very often PS correspond to man-made artefacts and to rocky outcrops.

\section{RESULTS}

One of the limitations of the PSI techniques are represented by the uncertainty of the detection of the measurement points [12]. Several tools for the assessment of the PSs presence in a given area have been developed in the scientific community [30-32]. For instance the R-index equation, conceived by Notti et al .[31-32] is defined as the ratio between the slant range and the ground range, taking also into account the acquisition geometry of the radar and the geometry of the ground surface. These last products are ascribable to the slope and aspect models, respectively, derived from a DEM. The maximum value of the R-index is 1 and corresponds to the best geometry to detect the PSs, when the slope is parallel to the LOS. Otherwise, the smaller is the R-Index, the harder to detect a PS: if this value tends to 0 it means that the pixel is in foreshortening, meanwhile it will be layover and shadowing if the Rindex results negative. In all these three cases no PS is detectable. The R-index computation for the descending dataset is shown in the Figure 3: the landslide area clearly corresponds to a non-detectable area for the PSs, specifically in foreshortening, meanwhile the RIndex for the ascending dataset shows a good quality of the pixels in the study area. Thanks to these elaboration, both the SUBSOFT processor and SARscape software have been successfully applied only at the ascending stack. 


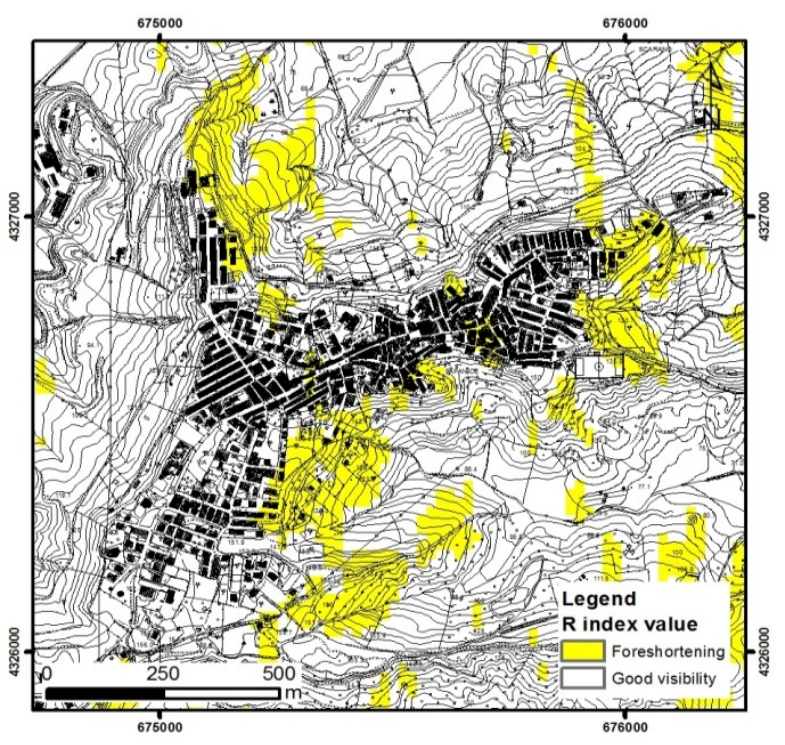

Figure 3. R-Index map for the descending dataset

\subsection{SUBSOFT processing}

As mentioned before, the results obtained with SUBSOFT processor have been carried out through the new TSC pixel selection method. A threshold of 0.7 , which corresponds to a phase standard deviation of about $20^{\circ}$ has been set to the TSSC approach. It is worth to point out that such selection fits almost perfectly the Papanice urban area. A total amount of about 9000 points located throughout the town has been obtained, one hundred of them are related to the displacement, located onto the top of the landslide of Via Piave, as it is possible to see in the Figure 4 . The average velocity of the displacement is $-27.7 \mathrm{~mm} / \mathrm{yr}$. The maximum rates of displacement are located in the left sector of the Via Piave landslide (-36.0 and $-35.6 \mathrm{~mm} / \mathrm{yr})$, other high rates are sited in correspondence of the main scarp of the landslide. Lower values of movement can be found in the right sector and down the valley of the slope of interest, with minimum rate of $14.8 \mathrm{~mm} / \mathrm{yr}$. All the values mentioned are calculated with respect to the Line of Sight (LOS).

\subsection{SARscape processing}

In order to improve the PSI processing results, using SARscape, the following procedure has been theorised and introduced:

- a temporal baseline, splitting in two parts the available stack (Period 1, between April 2008 and August 2009, and Period 2, between April 2009 and June 2010, with an overlap of 110 days), in order to analyse points with high coherence in a shorter time of analysis;

- a spatial baseline of $\pm 100 \mathrm{~m}$, a threshold useful to decrease the topography influence on the interferometric signal (Fig. 5).

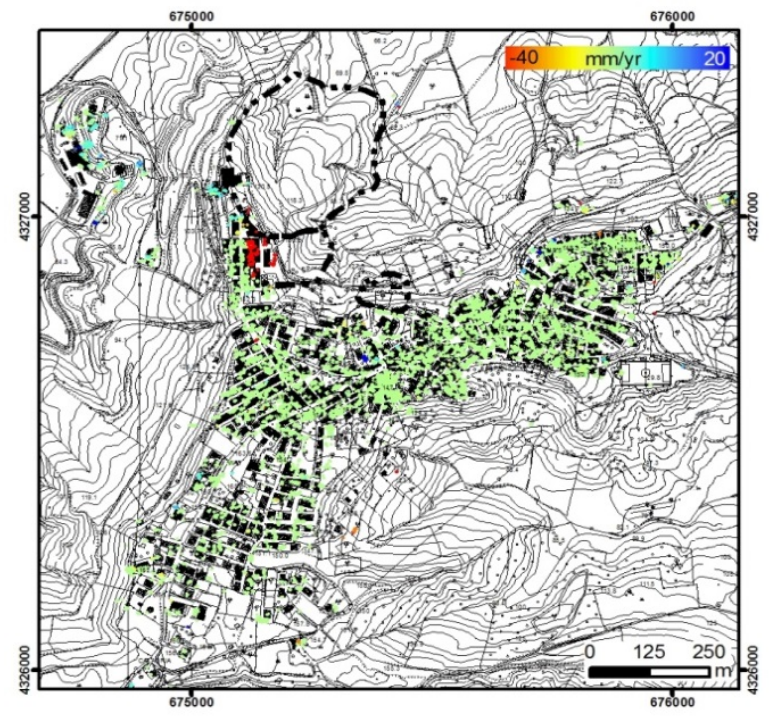

Figure 4. Displacement rate map with the TSC algorithm

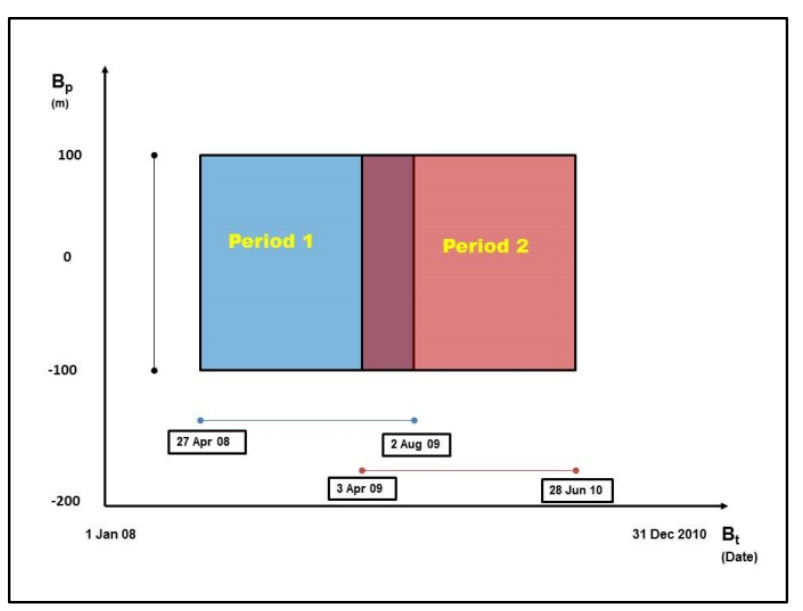

Figure 5. Scheme of the procedure theorised for the PSI analysis

The first period of investigation has been evaluated on 29 images. In this case a total amount of 1393 points has been obtained, and 7 of which show a displacement rate ascribable to the landslide. In particular the cluster of points, individuated by the PSI analysis, is located in the top left sector and in the middle part of the movement. The average value of these points is of -25.4 $\mathrm{mm} / \mathrm{yr}$. The highest displacement rates are all located into the top left sector of the Via Piave landslide, with a maximum value of $-32.1 \mathrm{~mm} / \mathrm{yr}$ (Fig. 6a). The second period is composed of 27 images. The sum of the PSs recognized is of 1543 , but just one is ascribable to the main phenomenon. This point, located into the top left part of the main landslide, close to the main scarp, present a displacement rate of $-32.1 \mathrm{~mm} / \mathrm{yr}$ (Fig. 6b). Also in these cases, the displacement values are referred 
along the LOS. For both of them, a product coherence threshold of 0.6 was selected, as the accuracy of PSI increases with increasing coherence.

\section{DISCUSSION}

From the comparison between the various results obtained with the two techniques exploited it is possible to affirm that, in every case, the landslide occurred on the $23^{\text {rd }}$ of February 2012 has been clearly recognized by MTI procedure, testified by the concentration of points located on the main scarp of the landslide. From an accurate analysis of the displacement rates derived from both the methods, a concentration of points characterized by the highest values of movement has been recognized in the top left sector of the landslide of Via Piave. A confirmation of this remark has been also achieved with other techniques implemented on the two packages used (CPT - coherence pixel selection and Small Baseline Subset). This fact can be attributed to geomorphological factors: usually the movements are faster in correspondence of the main scarp, and in this case, also the presence of a seasonal stream can have had a role in it.

Moreover, following these results, it is also possible to update the landslide inventory map of Papanice, redacted in the 2001 HSP by the Calabria Basin Authority. First of all, the landslide objects of the paper were considered as dormant, meanwhile, from a jointly application of ground surveys and remote sensing, they are clearly updatable as active. Besides, also a retrogressive trend has been recognized, as proved by the actual landslide scarp, now located at Via Piave. The benefit deriving from these spaceborne MTI techniques as worthwhile tools for the delimitation of surface movements were demonstrated always in agreement with field validation. Also the time series show a good connection with the rainfalls data, in fact the accelerations of the movement is subsequent to abundant precipitations, as well as the deceleration to dry periods. It is also worth to underline that, being the TerraSAR-X dataset antecedent to the landslide's main reactivation, the SAR exploitation is an useful device to recognize precursor stages of future slope failures. As regards to the comparison between the two techniques applied for this case study, many similarities, but also some differences, have been recognized: the range of the velocities and the location of the pixels showing displacement proved to be the same for both the MTI procedures adopted, demonstrating a good reliability of these kinds of data (Fig. 7). However, the final results of the application of SUBSOFT showed a higher number of targets, with respect to the SARscape application (9000 to 1500 approximately). Moreover, also a higher number of points located in the displacement area enables detailed analysis of surface movements. Furthermore, as regards to the SARscape results, they showed a shift of the PSs of about $150 \mathrm{~m}$ westward, hence necessitating
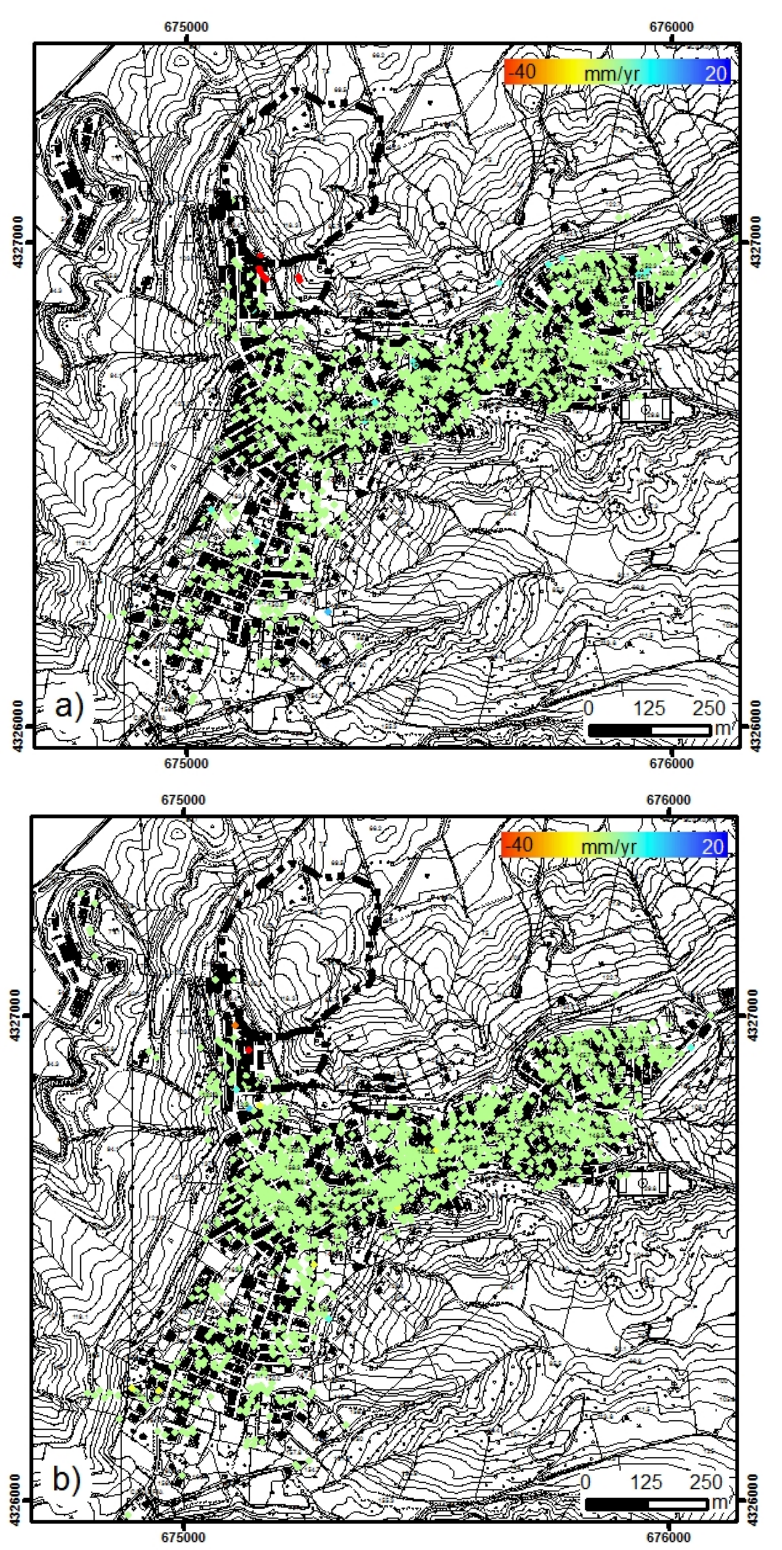

Figure 6. Displacement rate map with the PSInSAR algorithm. A) First period of analysis (04/2008-

08/2009); b) Second period of analysis(04/200906/2010)

a correction through the individuation of ground control points, meanwhile the geocoding of the SUBSOFT software turned out to be correctly georeferenced, without any shift.

\section{CONCLUSIONS}

DInSAR techniques represent a powerful tool for landslide forecasting and monitoring, even more efficient when coupled with geological and geomorphological field surveys. First of all, the application of tools which can provide a first estimation of the potential PS in an area can help the user to select only the valuable stacks. 


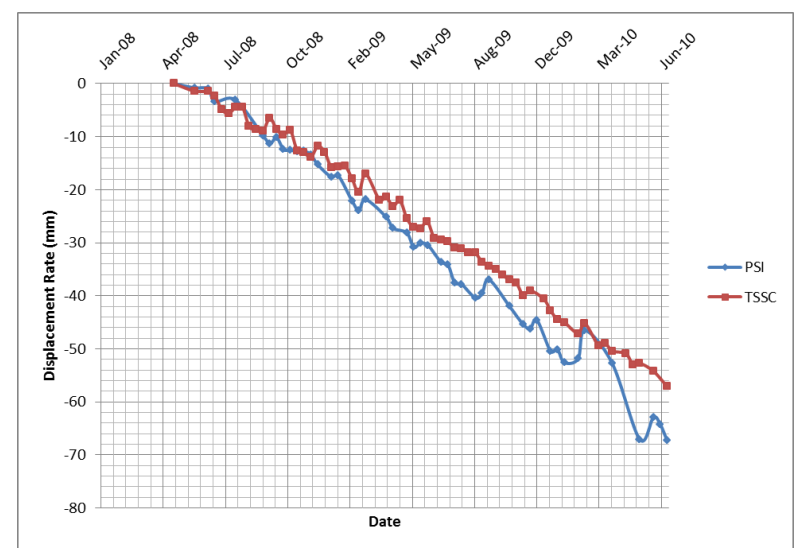

Figure 7. Comparison between the time series obtained with SUBSOFT and SARscape.

Moreover, the application of various Multi Temporal Interferometry approaches, even with some differences, demonstrating comparable results, can confirm the reliability of these instruments. The availability of conventional ground-based monitoring instruments (inclinometers, topographic total stations, etc.) can improve the trustworthiness of the satellite observations, which they can be considered as an useful supporting tool for urban planning and landslide hazard assessment on behalf of public agencies and administrations, due to their ability to obtain good results in a short time. Also the application of these methods for regular time monitoring shortly after each acquisition can help to prevent damage on areas considered at risk. In the future, the second stage of the Italian Extraordinary Plan for Environmental Remote Sensing and the availability of VHR last generation images acquired by TerraSAR-X, COSMO-SkyMed and SENTINEL-1 sensors will allow us to obtain better results.

\section{ACKNOWLEDGMENTS}

TerraSAR-X data have been provided by the German Aerospace Center (DLR) through the GEO1589 and the GEO2641 projects. Authors would like to thank Prof. J.J. Mallorquì (Remote Sensing Laboratory of the Universitat Politècnica de Catalunya of Barcelona) for providing the SUBSOFT processor, and the department of GeoRisks and Civil Security (DLR) for the access to SARscape. Thanks are also due to ARPACAL (Regional Agency for Environmental Protection of Calabria Region) for providing rainfall and geological data.

\section{REFERENCES}

1. Ferretti, A., Prati, C., Rocca, F. (2001). Permanent Scatterers in SAR interferometry. IEEE Trans. Geosci. Remote Sens. 39, 8-20.
3. Mora, O., Mallorqui, J.J. \& Broquetas, A. (2003). Linear and non- linear terrain deformation maps from a reduced set of interferometric sar images.. IEEE Trans. Geosci. Remote Sens. 41, 2243-2253.

4. Blanco-Sanchez, P., Mallorquí, J. J., Duque, S., \& Monells, D. (2008). The coherent pixels technique (CPT): An advanced DInSAR technique for nonlinear deformation monitoring. Pure and Applied Geophysics, 165(6), 1167-1193.

5. Iglesias, R., Mallorqui, J. J., Monells, D., López-Martínez, C., Fabregas, X., Aguasca, A., Gill J. A. \& Corominas, J. (2015). PSI Deformation Map Retrieval by Means of Temporal Sublook Coherence on Reduced Sets of SAR Images. Remote Sensing, 7(1), 530-563.

6. Superior Institute for Environmental Protection and Research (2014). Summary report on the hydro-geomorphological instability in Italy. (In Italian)

7. Berti, D., Guarnieri, E.M. \& Silvestri, S., (2003). The flood event of the 23-27 January 2003 in Molise region. Analysis of the effects on geomorphological and hydraulic risk. Technical report, APAT. (In Italian)

8. Calcaterra, D., Ramondini, M., Calò, F., Longobardi, V., Parise, M. \& Galzerano, C.M. (2008). DInSAR techniques for monitoring slow-moving landslides. Landslides and Engineered Slopes, Taylor \& Francis Group, London, 1095-1101.

9. Guerriero, L., Revellino, P., Coe J., Focareta, M., Grelle, G., Albanese, V., Corazza, A. \& Guadagno F.M. (2013). Multi-temporal Maps of the Montaguto Earth Flow in Southern Italy from 1954 to 2010. Journal of Maps, 9(1), 135-145.

10. Calò, F., Parise, M., Ramondini, M. \& Singhroy, V., (2009). Application of DInSAR techniques to the monitoring of intermittent slope movements in the Southern Apennines of Italy. Fringe 2009 Workshop, Frascati, Italy.

11. Di Martire, D., Ramondini, M. \& Calcaterra, D. (2014). Integrated monitoring for slow landslide risk evaluation: a case study. $X X V$ Convegno Nazionale di Geotecnica, Baveno,

2. www.sarmap.ch 
Italy, 2014. ISBN 978-88-97517-05-4 (In Italian)

12. Colesanti, C. \& Wasowski, J. (2006). Investigating landslides with space-borne Synthetic Aperture Radar (SAR) interferometry. Engineering Geology, 88, 173-199.

13. Cascini, L., Fornaro, G., \& Peduto, D. (2010). Advanced low- and full-resolution DInSAR map generation for slow-moving landslide analysis at different scales. Engineering Geology, 112, 29-42.

14. Di Martire, D., Iodice, A., Ramondini, M., Ruello, G. \& Calcaterra D. (2011). Combined observations of surface displacements using Differential Interferometry SAR (DInSAR) and traditional monitoring techniques. Proc. 8th Intern. Symp. on Field Measurements in GeoMechanics, Berlin, Germany, September 12-16, 2011, 13 pp.

15. Calò, F., Calcaterra, D., Iodice, A., Parise, M., \& Ramondini, M. (2012). Assessing the activity of a large landslide in southern Italy by ground-monitoring and SAR interferometric techniques. International Journal of Remote Sensing, 33(11), 3512-3530.

16. Herrera, G., Gutierrez, F., Garcìa-Davalillo, J. C., Guerrero, J., Notti, D., Galve, J. P., Fernandez-Merodo, J.A. \& Cooksley, G. (2013). Multi-sensor advanced DInSAR monitoring of very slow landslides: The Tena Valley case study (central Spanish Pyrenees). Remote Sensing of Environment, 128, 31-43.

17. Ciampalini, A., Bardi, F., Bianchini, S., Frodella, W., Del Ventisette, C., Moretti, S., \& Casagli, N. (2014). Analysis of building deformation in landslide area using multisensor PSInSAR $^{\mathrm{TM}}$ technique. International Journal of Applied Earth Observation and Geoinformation, 33, 166-180.

18. Wasowski, J. \& Bovenga, F. (2014). Investigating landslides and unstable slopes with satellite multi temporal interferometry: current issues and future perspectives. Engineering Geology, 174, 103-138.

19. Bovenga, F., Nutricato, R., Refice, A. \& Wasowski, J. (2006). Application of multitemporal differential interferometry to slope instability detection in urban/peri-urban areas. Engineering Geology, 88(3), 218-239.
20. Roda, C. (1964). Facies and distribution of Neogenic sediments in the Crotone Basin. Geologica Romana, 3, 319-366. (In Italian)

21. Van Dijk, J.P. (1990). Sequence stratigraphy, kinematics and dynamic geohistory of the Crotone Basin (Calabria Arc, Central Mediterranean): an integrated approach. Memorie della Società Geologica Italiana, 44, 259-285.

22. Meulenkamp, J.E., Hilgen, F. \& Voogt, E., (1986). Late Cenozoic sedimentary tectonic history of the Calabrian Arc. Giornale di Geologia, 48(1-2), 345-359.

23. Van Dijk, J.P. (1990). Sequence stratigraphy, kinematics and dynamic geohistory of the Crotone Basin (Calabria Arc, Central Mediterranean): an integrated approach. Memorie della Società Geologica Italiana, 44, 259-285.

24. Van Dijk, J.P. (1991). Basin dynamics and sequence stratigraphy in the Calabrian Arc (Central Mediterranean): records and pathways of the Crotone Basin. Geologie en Mijnbouw, 70, 187-201.

25. Van Dijk, J.P. \& Okkes, F.W.M. (1990). The analysis of shear zones in Calabria: Implications for the geodynamics of the Central Mediterranean. Ric. Sci., Suppl., 68, 24-27.

26. CASMEZ (1967). Geological Sheet Cutro n. 238, scale $1: 25.000$.

27. Van Dijk, J.P. \& Okkes, F.W.M. (1991). Neogene tectonostratigraphy and kinematics of Calabrian basins; implications for the geodynamics of the Central Mediterranean. Tectonophysics, 196, 23-60.

28. Massari, F., Rio, D., Sgavetti, M., Prosser, G., D'Alessandro, A., Asioli, A., Capraro, L., Fornaciari, E. \& Tateo, F. (2002). Interplay between tectonics and glacio-eustasy: Pleistocene succession of the Crotone basin, Calabria (southern Italy).Geological Society of America Bulletin, 114(10), 1183-1209.

29. Zecchin, M., Caffau, M., Civile D., Critelli, S., Di Stefano, A., Maniscalco, R., Muto, F., Sturiale, G. \& Roda, C. (2012). The PlioPleistocene evolution of the Crotone Basin (southern Italy): Interplay between sedimentation, tectonics and eustasy in the frame of Ca- 
labrian Arc migration. Earth-Science Reviews: 115(4), 273-303.

30. Plank, S., Singer, J. \& Thuro, K. (2013). Assessment of number and distribution of persistent scatterers prior to radar acquisition using open access land cover and topographical data. ISPRS Journal of Photogrammetry and Remote Sensing, 85, 132-147.

31. Notti, D., Davalillo, J.D., Herrera, G. \& Mora, O. (2010). Assessment of the performance of $\mathrm{X}$-band satellite radar data for landslide mapping and monitoring: Upper Tena Valley case study. Natural Hazards and Earth System Sciences, 10, 1865-1875.

32. Notti, D., Herrera, G., Bianchini, S., Meisina, C., García-Davalillo, J.C. \& Zucca, F. (2014). A methodology for improving landslide PSI data analysis. International Journal of Remote Sensing, 35(6), 2186-2214. 